\title{
KUALITAS PELAYANAN PUBLIK PADA DINAS KEPENDUDUKAN DAN PENCATATAN SIPIL KABUPATEN BENGKULU TENGAH
}

\author{
Oleh : \\ ANTONIO IMANDA \\ Dosen Prodi Administrasi Publik Fakultas Ilmu Sosial UNIVED Bengkulu
}

\begin{abstract}
Public service is a very crucial and interesting issue to discuss because it always exists in a state where the state and the administration stands. The implementation of public service is still far from the ideal expectation of the public. The identification of the unexpected services is visible in terms of the waiting and public services which often face uncertainly. It is very difficult to estimate when the services can be obtained, and on the other side it sometimes needs some unofficially fee to undergo the process of getting the services. This research aims to find out the quality of public services at the office of population and civil registry in Bengkulu Tengah regency. This research uses a descriptive qualitative approach. The data used in this research is secondary and primary data. In the data collection, the researcher uses triangulation technique and the researcher uses informants by purposive sampling technique. The data process and analysis were carried out by means of data reduction, presentation, and making conclusion. From the research results and discussion, the poor quality of public services in Bengkulu Tengah was caused by; 1) low level of consistency between the waiting time and the processing time, 2) common mistakes about the accuracy of the services especially regarding errors in the printing of the document, 3) lack of courtesy and hospitality of the employees as well as lack of mutual respect of the clerk, 4) the employees have weak sense of responsibility in providing services, especially regarding discipline employees, 5) the administration wares of making identity cards shows that it is easier to get, but it is different from the wares of making the family cards, in which it shows some more difficult, 6) it is still rather difficult to get the services, the frequent discriminatory attitudes, the lack amount of employees, and moreover the wares such as computer and other facilities are still limited, 7) no variation of service model, 8) the low level of personal services provided by the officers, 9) there is no comfort in obtaining the services, 10) the unavailability of supporting facilities, clean environment and enjoyable circumstance. Then, the environment also has lack of regularity, neatness, tidiness and cleanliness. Based on the conclusion above, the government should develop the human resources in both the quantity and the quality in order to be able to improve the services including the employees' discipline enforcement, improving apparatus' mental through the provision of punishment and reward, and structured of the standard of procedure operational, the increase in the means of supporting driven computerized technologies and a more adequate office lies in a strategic area and circumstance.
\end{abstract}

Keywords : quality of public services, civil registry 


\section{PENDAHULUAN}

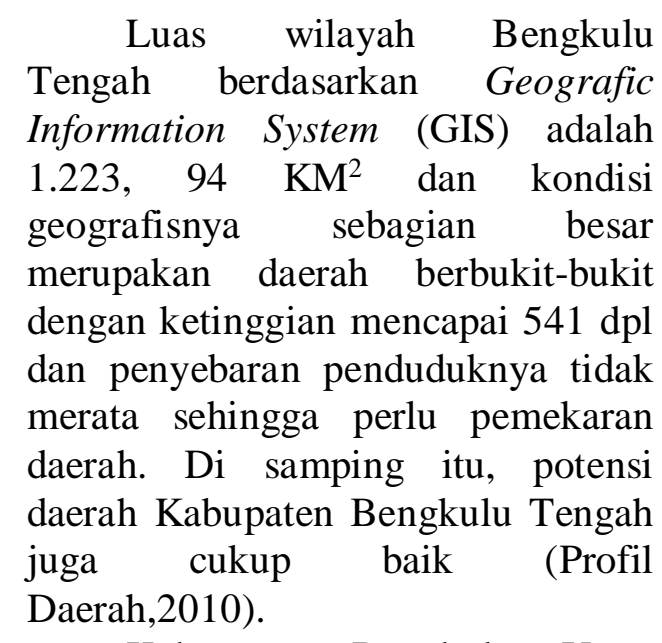

Kabupaten Bengkulu Utara diusulkan untuk dimekarkan dan disetujui oleh sidang Paripurna DPRRI. Dari persetujuan itu maka lahirlah Kabupaten Bengkulu Tengah yang terbentuk berdasarkan Undangundang nomor 24 tahun 2008 tanggal 24 Juni 2008 dan diundangkan tanggal 21 Juli 2008.

\section{Lahirnya kebijakan} pemerintah ini membawa dampak bagi kabupaten Bengkulu Utara sebagai kabupaten induk maupun bagi kabupaten baru, misalnya berubahnya luas dan tata batas daerah, berkurangnya penerimaan pendapatan daerah khususnya bagi kabupaten induk, dan dekatnya pusat pelayanan kepada masyarakat sehingga memungkinkan adanya peningkatan terhadap kualitas pelayanan publik.

Pelayanan merupakan tugas utama yang hakiki dari aparatur pemerintah sebagai abdi negara dan abdi masyarakat. Tugas ini telah jelas digariskan dalam pembukaan UUD 1945 alinea keempat, yang meliputi 4 (empat) aspek pelayanan pokok aparatur terhadap masyarakat, salah satunya yaitu memajukan kesejahteraan umum.

Penelitian yang dilakukan oleh Dwiyanto (2002) menyimpulkan bahwa kinerja pelayanan birokrasi publik di daerah masih rendah, praktik korupsi, kolusi, dan nepotisme (KKN) dalam pemerintahan dan dalam pelayanan publik masih terus berlangsung, bahkan dengan skala dan pelaku yang semakin meluas, keinginan masyarakat untuk menikmati pelayanan publik yang efisien, responsif, akuntabel masih amat jauh dari realitas.

Sedarmayanti

menggambarkan kondisi pelayanan publik di Indonesia sebagai berikut :

a. Diskriminasi pelayanan : perbedaan perlakuan oleh penyedia pelayanan karena status sosial dan ekonomi pengguna.

b. Ketidak pastian pelayanan: ketidak pastian prosedur, waktu dan biaya pelayanan.

c. Tingkat kepuasan masyarakat terhadap pelayanan publik belum memuaskan.

d. Tidak ada sistem insentif: system insentif mampu mendorong pejabat birokrasi bekerja efisien dan professional.

e. Kewenangan monopoli yang memiliki birokrasi pelayanan publik membuat birokrasi gagal mengembangkan budaya dan tradisi kompetensi, akibatnya birokrasi kehilangan dorongan dan insentif meningkatkan efisiensi dan kualitas pelayanan.

Studi pendahuluan penulis menunjukkan bahwa jumlah anggota masyarakat yang belum terlayani masih lebih besar dibandingkan dengan jumlah anggota masyarakat 
yang sudah terlayani. Kenyataan tersebut disebabkan selain faktor geografis juga lemahnya pelayanan oleh petugas baik secara administratif maupun teknis. Kondisi demikian sesuai dengan apa yang disampaikan oleh sala satu informan mengatakan tidak mungkin mereka mendapatkan pelayanan yang baik, aparat pemerintahan saja masuk kedesa mereka mungkin malas karena kondisi jalannya sangat buruk. Bukan Cuma desa mereka yang kondisinya demikian, hampir seluruh kecamatan di Bengkulu Tengah ini masih seperti ini. Jangankan pemerintah kadang mereka sendiri malas keluar dari desa ini karena sulitnya melewati jalan yang demikian yang kadang kala banjir (studi pendahuluan penulis, 9 November 2011)

Kenyataan tersebut tidak saja disebabkan oleh berbagai hambatan sebagaimana disebutkan di atas, melainkan masih ada hal lain yang menjadi penyebabnya, seperti dalam memberikan pelayanan publik tidak diikuti oleh peningkatan kualitas birokrasi yang memberikan pelayanan kepada masyarakat. Kualitas dan kinerja birokrasi dalam memberikan pelayanan publik masih jauh dari harapan. Masih belum tercipta budaya pelayanan publik yang berorientasi kepada pelayanan pelanggan (service delivery culture), kompetensi birokrat masih belum memadai, prosedur pelayanan masih berbelit-belit, dan harga pelayanan publik masih tidak transparan (Ratminto \& Winarsih, 2007, 207)

Permasalahan yang akan dilihat dalam penelitian ini adalah seputar pelayanan yang dilakukan yaitu pelayanan pembuatan Kartu keluarga, pembuatan KTP, Pembuatan Akta Nikah dan Akta Lahir.

Kebijakan pemekaran daerah membawa dampak bagi kabupaten yang baru dimekarkan khususnya dalam bidang pelayanan publik. Untuk melihat apakah pemekaran daerah tersebut membawa dampak positif bagi peningkatan kualitas pelayanan publik, maka penulis melihat kualitas pelayanan publik pada salah satu dinas yaitu Dinas Kependudukan dan Pencatatan Sipil Kabupaten Bengkulu Tengah.

Pelayanan publik adalah isu yang sangat krusial dan menarik untuk didiskusikan karena isu tentang pelayanan publik tidak ada putus-putusnya selama negara masih berdiri dan pemerintahannya masih eksis, walaupun dalam prakteknya selalu saja publik berada pada posisi tawar yang tidak seimbang dengan pemerintah. Pemerintah sebagai pemeran utama birokrasi cenderung membuat prosedur dan mekanisme kerja pelayanan yang berbelit-belit dan rumit sehingga sulit untuk dimengerti oleh masyarakat kelas bawah. Sebagaimana diungkapkan oleh Ratminto dan Atik Septi Winarsih (2007,207), banyak pengaduan dan keluhan dari masyarakat mengenai prosedur dan mekanisme kerja pelayanan yang berbelit-belit, tidak transparan, kurang akomodatif, kurang konsisten, terbatasnya fasilitas, sarana dan prasarana pelayanan, sehingga tidak menjamin kepastian hukum, waktu dan biaya serta masih banyak dijumpai praktek pungutan liar dan tindakan-tindakan yang berindikasikan penyimpangan seperti kolusi, korupsi dan nepotisme. 
Utomo (2002) menilai bahwa organisasi publik umumnya buruk pelayanannya. Dikatakannya, ketidakmampuan birokrasi menjadi atau memberikan pelayanan publik dikarenakan: Pertama, birokrasi berada dan bekerja pada lingkungan yang hirarkis, birokratis, monopolis dan terikat oleh political authority, akibatnya kaku atau rigid, following the instruction, dan tidak memiliki inisiatif serta kreatifitas. Kedua, birokrasi sarat dengan tugas dan fungsi yang tidak terfokus kepada pelayanan publik, tetapi juga bertugas sebagai motor pembangunan dan aktivitas pemberdayaan sehingga membuatnya tidak lincah bergerak. Untuk memperbaiki kondisi itu maka fungsi birokrasi harus dikembalikan kepada fungsi yang sebenarnya yaitu sebagai public service.

Untuk dapat menilai sejauh mana kualitas pelayanan publik yang diberikan oleh aparatur pemerintah, perlu ada kriteria yang menunjukkan apakah suatu pelayanan publik yang diberikan dapat dikatakan baik atau buruk. Ciri-ciri atau atribut-atribut yang menentukan harus diperhatikan dalam perbaikan kualitas pelayanan publik menurut Gaspersz (dalam Sedarmayanti 2009, 257) antara lain :

1. Ketepatan waktu pelayanan, yang meliputi waktu tunggu dan waktu proses

2. Akurasi pelayanan, yang meliputi bebas dari kesalahan

3. Kesopanan dan keramahan dalam memberikan pelayanan

4. Tanggung jawab meliputi kejelasan wewenang dan tanggung jawab petugas dalam penyelenggaraan dan penyelesaian pelayanan
5. Kelengkapan

6. Kemudahan mendapatkan pelayanan, misalnya banyaknya petugas yang melayani dan banyaknya fasilitas pendukung seperti komputer;

7. Variasi Model pelayanan;

8. Pelayanan pribadi;

9. Kenyamanan dalam memperoleh pelayanan, berkaitan dengan lokasi, ruang tempat pelayanan, tempat parkir, ketersediaan informasi dan lain-lain;

10. Atribut pendukung pelayanan lainnya seperti ruang tunggu ber$\mathrm{AC}$, kebersihan dan lain-lain.

Sebagai frame dalam melakukan research, analisis data, dan penyajian data sehingga terintegrasi dalam satu garis pemikiran dan tidak bias, maka penulis dalam melakukan penelitian menggunakan metode penelitian yang bersifat deskriptif, dengan pendekatan kualitatif. Tujuannya adalah untuk pengukuran yang cermat terhadap fenomena sosial tertentu, dengan mengembangkan konsep dan menghimpun fakta tetapi tidak melakukan pengujian hipotesis Pendekatan yang digunakan adalah studi kasus (case study), yaitu suatu pendekatan penelitian yang penelaahannya diarahkan pada satu kasus secara intensif, mendetail dan mendalam.

Aspek - aspek yang akan diteliti dalam penelitian ini adalah kualitas pelayanan publik yang mana akan diukur dari tingkat kepuasan pengguna jasa terhadap kualitas pelayanan yang diberikan, yaitu :

1. Ketepatan waktu pelayanan, yang meliputi waktu tunggu dan waktu proses;

2. Akurasi pelayanan, yang meliputi bebas dari kesalahan; 
3. Kesopanan dan keramahan dalam memberikan pelayanan;

4. Tanggung jawab meliputi kejelasan wewenang dan tanggung jawab petugas dalam penyelenggaraan dan penyelesaian pelayanan;

5. Kelengkapan;

6. Kemudahan mendapatkan pelayanan, misalnya banyaknya petugas yang melayani dan banyaknya fasilitas pendukung seperti komputer;

7. Variasi Model pelayanan;

8. Pelayanan pribadi;

9. Kenyamanan dalam memperoleh pelayanan, berkaitan dengan lokasi, ruang tempat pelayanan, tempat parkir, ketersediaan informasi dan lain-lain;

10. Atribut pendukung pelayanan lainnya seperti ruang tunggu ber$\mathrm{AC}$, kebersihan dan lain-lain.

\section{METODE PENELITIAN}

Data yang digunakan dalam adalah data sekunder dan primer. Informan dalam penelitian ini adalah pegawai di Dinas Dukcapil kepala seksi mutasi penduduk yang menangani pembuatan KTP dan KK serta kepala bidang kelahiran dan kematian yang menangani pembuatan Akte. Informan berikutnya yaitu 5 orang dari unsur masyarakat yang dianggap mempunyai informasi.. Total jumlah jumlah informan sebanyak 7 orang.

Teknik pengumpulan data dalam penelitian ini menggunakan triangulasi yaitu menggabungkan berbagai teknik pengumpulan data dan sumber data yang telah ada
(Sugiono, 2007, 241). Triangulasi yang dimaksudkan yaitu :

a. Triangulasi Teknik

b. Triangulasi Sumber

Untuk mengumpulkan data dari sumber yang berbeda dengan teknik yang sama, peneliti melakukan wawancara mendalam dengan beberapa informan yang berbeda tentang fokus penelitian.

Untuk mendapatkan data yang tepat, maka penulis menentukan informan dengan menggunakan tekhnik insidental sampling untuk informan dari unsur masyarakat dan purposive sampling informan dari unsur pegawai.

Aktivitas dalam analisis data;
a. Data reduction
b. Data display
c. Conclusion drawing/verification

\section{HASIL PENELITIAN DAN PEMBAHASAN}

Berdasarkan hasil penelitian diketahui bahwa terdapat fenomena yang menggambarkan permasalahan dalam pelayanan publik yang selama ini dirasakan oleh masyarakat Kabupaten Bengkulu Tengah. Masyarakat Kabupaten Bengkulu Tengah mengeluh terhadap penyelenggaraan pelayanan publik yang dirasakan tidak sesuai dengan harapannya. Meskipun begitu ternyata belum ada upaya perbaikan yang berarti dalam penyelenggaraan pelayanan publik, meskipun ide awal pemekaran yang diharapkan masyarakat salah satunya adalah untuk meningkatkan kualitas pelayanan publik. Dari hasil analisis dan interpretasi data, dapat diambil kesimpulan bahwa masih rendahnya 
kualitas pelayanan publik Dinas Kependudukan dan Pencatatan Sipil Kabupaten Bengkulu Tengah, yang disebabkan antara lain :

1. Masih tidak konsistennya antara waktu tunggu dengan waktu penyelesaian dalam memberikan pelayanan kepada masyarakat, masih banyak terjadi kesalahan dalam akurasi pelayanan berkaitan dengan pelayanan yang diberikan, terutama mengenai hal-hal teknis, misalnya kesalahan dalam pencetakan dokumen.

2. Masih kurang dan rendahnya sopan santun dan keramahan serta kurangnya sikap saling menghormati dan menghargai dari petugas yang memberikan pelayanan kepada masyarakat yang menerima pelayanan.

3. Masih lemahnya rasa tanggung jawab petugas dalam memberikan pelayanan kepada masyarakat, terutama mengenai kedisiplinan pegawainya.

Kedisiplinan pegawai menjadi permasalahan yang krusial karena menghambat pelaksanaan tugas pelayanan.

4. Dalam hal kelengkapan administrasi pembuatan KTP dan KK menunjukkan adanya kemudahan, namun untuk pembuatan Akta Kelahiran dan Akta Nikah agak sedikit rumit. Meskipun demikian prosedur untuk menyelesaikan urusan tidak berbelit-belit, mudah dilaksanakan serta dipahami walaupun prosedur tersebut tidak mencantumkan biaya pembuatan.

5. Masih sulitnya masyarakat mendapatkan pelayanan, terbukti dengan seringnya terjadi perlakuan diskriminatif petugas terhadap pengguna jasa pelayanan. Kekurangan jumlah pegawai yang bertugas pada bagian peyanan, serta fasilitas komputer pada bagian pelayanan masih terbatas, menjadi kendala dalam peningkatan kualitas pelayanan.

6. Tidak ada variasi model pelayanan yang dilakukan oleh Dinas DUKCAPIL Kabupaten Bengkulu Tengah, hal ini belum sejalan dengan program nasional tentang reformasi pelayanan publik, ditambah lagi daya inisiatif dan kreativitas petugas yang rendah dan terlalu prosedural.

7. Masih sangat rendahnya kepedulian dan empati yang diberikan oleh petugas pelayanan pada Dinas DUKCAPIL Kabupaten Bengkulu Tengah terhadap masyarakat dalam menghadapi permasalahanpermasalahannya.

8. Belum ada kenyamanan dalam memperoleh pelayanan karena tidak tersedia dan masih terbatasnya fasilitas pendukung pelayanan, informasi tentang pelayanan.

\section{PENUTUP}

Berdasarkan beberapa aspek yang diteliti mengenai kualitas pelayanan publik di Dinas DUKCAPIL Kabupaten Bengkulu Tengah, maka yang harus dilakukan oleh Pemerintah Daerah Kabupaten Bengkulu Tengah untuk melakukan beberapa langkah sebagai berikut :

1. Perlu adanya peningkatan sumber daya manusia (SDM) baik secara kualitas maupun kwantitas agar 
mampu meningkatkan pelayanan kepada masyarakat kearah lebih baik lagi.

2. Perlu adanya penegakan disiplin, pengawasan dan pembenahan mental aparatur sebagai abdi masyarakat melalui pemberian punishman dan reward kepada aparatur terutama untuk mengatasi hal-hal yang berkaitan dengan pungutan liar yang ada di Dinas DUKCAPIL Kabupaten Bengkulu Tengah.

3. Perlu disusun standar operasional prosedur (SOP) untuk kemudahan informasi bagi masyarakat tentang alur pelayanan yang diberikan oleh di Dinas DUKCAPIL Kabupaten Bengkulu Tengah dan diharapkan SOP yang telah disusun tersebut, juga menjadi pedoman atau acuan kerja bagi aparatur/pegawai pada Dinas DUKCAPIL sehingga pelaksanaan tugas berjalan lancar, efektif, dan efisien, serta dapat dipertanggungjawabkan dan terhindar dari kesalahan dalam pelaksanaannya guna mewujudkan akuntabilitas kinerja di lingkungan Dinas DUKCAPIL.

4. Perlu adanya peningkatan sarana penunjang terutama teknologi komputerisasi dan kantor yang lebih memadai dan terletak pada lokasi yang strategis dalam memberikan pelayanan maksimal kepada masyarakat.

\section{DAFTAR PUSTAKA}

Dwiyanto, Agus. 1995. Manfaat Pengembangan Studi Kebijakan Publik untuk Pembangunan Daerah. Yogyakarta, UGM

Ratminto \& Winarsih Atik Septi .1999. Manajemen Pelayanan. Yogjakarta, Pustaka Pelajar

Sedarmayanti. 2009. Reformasi Administrasi Publik, Reformasi Birokrasi dan Kepemimpinan Masa Depan (mewujudkan Pelayanan prima dan kepemrintahan yang baik), Bandung, Refika Aditama

Sugiyono. 2007. Metode Penelitian Kuantitatif Kwalitatif dan $R \& D$. Bandung, Alpabeta

Utomo, Warsito.1997. Implementasi Desentralisasi dan Otonomi Daerah Tingkat II Masa Orde Baru (Studi Kasus di Dati II Cilacap dan Dati II Kudus) dalam JKAP Volume 1 Nomor 2 (Juli 1997). Yogyakarta, MAP UGM

Undang-undang Nomor 24 Tahun 2008 tentang Pembentukan Kabupaten Bengkulu Tengah

Profil Daerah Kabupaten Bengkulu Tengah Tahun 2010 